Japan. J. Med. Sci. Biol., 42, 39-49, 1989.

\title{
HIGH ACTIVITY OF ACID PHOSPHATASE OF PSEUDOMONAS PSEUDOMALLEI AS A POSSIBLE ATTRIBUTE RELATING TO ITS PATHOGENICITY
}

\author{
Surang DEJSIRILERT, Raywadee BUTRAPORN, Dumrong CHIEWSILP, \\ Eiko KONDO and Koomi KANAI
}

National Institute of Health, 88/7 Gp 4 Soi Bamrasnaradura Hospital, Trad Khuan District, Amphur Muang, Nonthaburi 11000, Thailand

(Received May 29, 1989. Accepted October 6, 1989)

SUMMARY: Phosphatase activities were compared quantitatively among selected species of pseudomonads. $P$. pseudomallei showed the highest activity of a bell-shaped $\mathrm{pH}$ pattern with a peak at around $\mathrm{pH}$ 5.0. P. cepacia had a similar pattern of milder intensity. In contrast, $P$. aeruginosa revealed an alkaline phosphatase activity with a $\mathrm{pH}$ optimum higher than 8.0 , but the level of activity was much lower than those of the above two species. The enzymatic reactions of other species were slight or negligible at their optimum $\mathrm{pH}$ in the same test system. These data were discussed in reference to their growth behavior in different $\mathrm{pH}$ environments and also in connection with such recent information that the high activity of microbial acid phosphatase may be a favorable attribute to their intracellular parasitism.

\section{INTRODUCTION}

One of the present authors has once studied on mycobacterial phosphatase with special concern to species-specific $\mathrm{pH}$ activity patterns (1). The results revealed that each species has its characteristic $\mathrm{pH}$ optimum in the acid side, and that the level of activity is particularly high in the pathogenic species.

This kind of study was recently extended by us to pseudomonads as a part of our project on Pseudomonas pseudomallei. Our observations gave an impression that bacterial acid phosphatase may have some relation to the mechanism of 
pathogenicity at least partly. Such idea is recently emerging also from the enzymatic and metabolic studies on leishmania species (2) as a possible mechanism to make them survive within the phagolysosomal acid environment.

The present paper describes $p$-nitrophenyl phosphatase activities of selected species of pseudomonads, comparing both their qualitative ( $\mathrm{pH}$ activity pattern) and quantitative (intensity) aspects. Discussions will be made on their biological significance.

\section{MATERIALS AND METHODS}

Microorganisms: Twenty-five strains of 11 species of pseudomonads were employed to test for their phosphatase activities. They were of clinical or environmental origin and stored at room temperature in stock medium; $1.0 \%$ Bacto casitone (Difco, Detroit, MI), $0.3 \%$ yeast extract (Difco), $0.5 \% \mathrm{NaCl}$, and $0.4 \%$ agar (Difco), with $\mathrm{pH}$ adjusted to 7.0-7.2. Most of these strains were sent to our laboratory for confirmation (3) and identified by the standard biochemical and chemical tests $(4,5)$. The reference and type strains were obtained from the culture collections of Department of Microbiology, Gifu University School of Medicine, Japan; Department of Microbiology, Faculty of Veterinary Science, Chulalongkorn University, Thailand; and Department of Microbiology, Faculty of Medicine, Siriraj Hospital, Mahidol University, Thailand. These strains are listed in Table I along with the strain numbers.

Before use, they were subcultured on trypton glucose extract (TGE) agar (Difco). A colony developed on this agar was transferred to $3 \mathrm{ml}$ of nutrient broth (Difco). After 18 to 20 -hr of incubation at $30 \mathrm{C}$, the broth culture was inoculated on TGE agar with a cotton swab. The 18-20 hrs growth was then suspended in an appropriate amount of physiologic saline, and its optical density was adjusted to 10 with a Hitachi spectrophotometer model $100-20$ set at $420 \mathrm{~nm}$.

Substrate and buffer: As a substrate for the phosphatase reaction, $p$ nitrophenyl phosphate was employed. A fresh $0.2 \%$ solution was prepared immediately before each experiment. Acetate buffer solutions ranging from $\mathrm{pH} 3.2$ to 6.22 were prepared in $0.1 \mathrm{M}$. For $\mathrm{pH} 6.5$ buffer solution, $1.16 \mathrm{~g}$ of maleic acid was dissolved in $40 \mathrm{ml}$ of distilled water and $4 \% \mathrm{NaOH}$ was added to make its $\mathrm{pH}$ to 6.5. Then, the total volume was made up to $100 \mathrm{ml}$ with distilled water. Neutral and alkaline buffer solutions ranging from $\mathrm{pH} 7.0$ to 10.2 were prepared as $0.1 \mathrm{M}$ Tris-HCl buffer.

Determination of phosphatase activity: Phosphatase activity was determined with the reaction system consisting of $0.8 \mathrm{ml}$ of a buffer, $0.1 \mathrm{ml}$ of a bacterial suspension, and $0.1 \mathrm{ml}$ of a substrate solution. The reaction mixture was incubated in a water bath at $40 \mathrm{C}$ for $30 \mathrm{~min}$ and then $1.0 \mathrm{ml}$ of $0.5 \mathrm{M} \mathrm{NaOH}$ and $1.0 \mathrm{ml}$ of 
Table I. The list of pseudomonads employed in this study

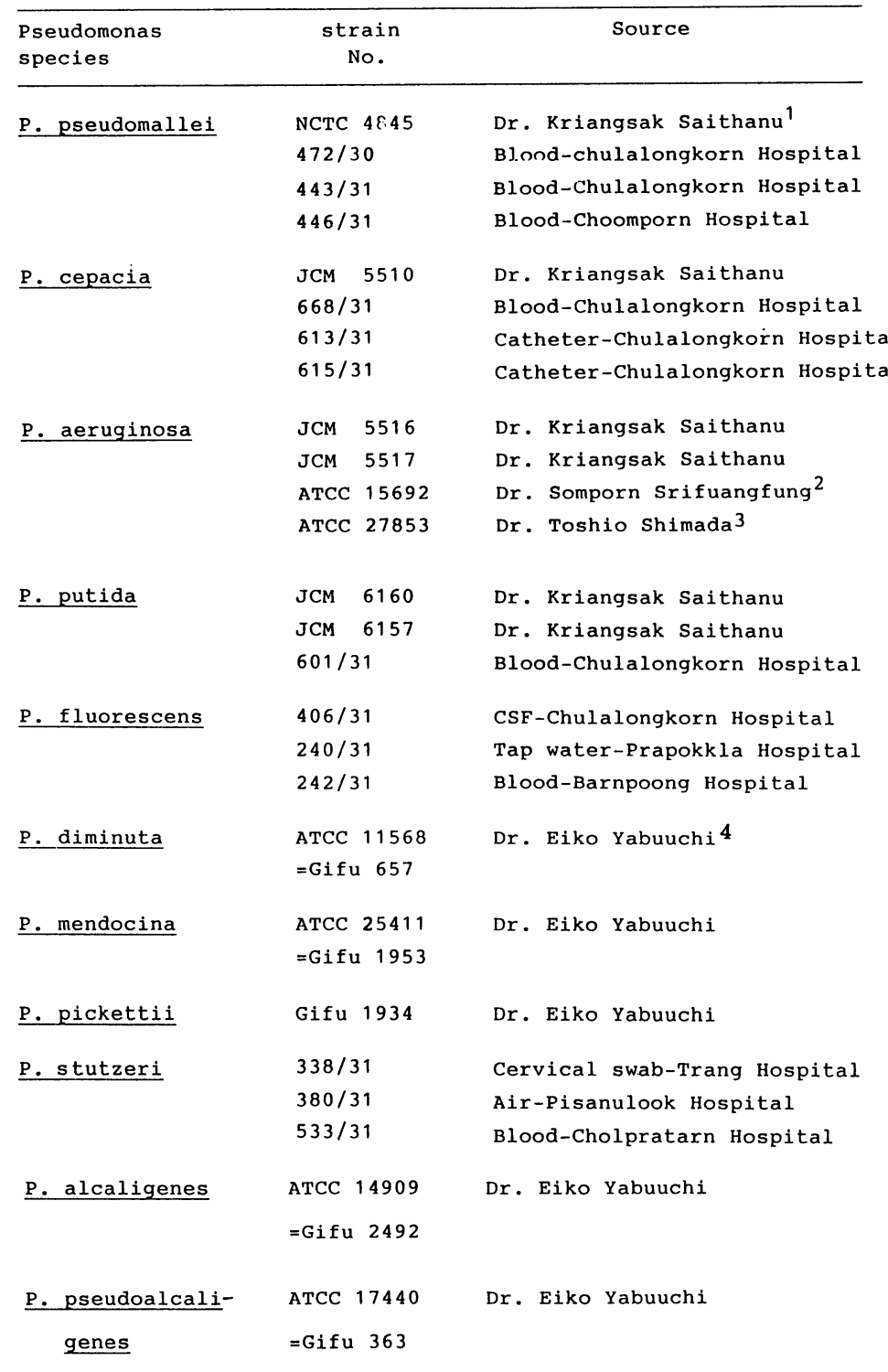

1. Department of Microbiology, Faculty of Veterinary Science, Chulalongkorn University, Thailand.

2. Department of Microbiology, Faculty of Medicine, Siriraj Hospital, Mahidol University, Thailand.

3. Department of Bacteriology, The National Institute of Health, Tokyo, Japan.

4. Department of Microbiology, Gifu University School of Medicine, Japan. 
distilled water were added, thus stopping the reaction and developing the yellow color of released $p$-nitrophenol. After centrifugation at 2,000 rpm for $10 \mathrm{~min}$, the clear supernatant of each reaction mixture was subjected to colorimetric determination with a Hitachi spectrophotometer set at $420 \mathrm{~nm}$. To the blank tube $\mathrm{NaOH}$ was added at zero time.

\section{RESULTS}

Biochemical and Biological Characters of Pseudomonad Strains Employed

Before the start of the present study, biochemical and biological characters of the pseudomonas strains to be employed were reexamined by the conventional methods $(4,5)$.

The results are shown in Table II identifying their species.

\section{Species Difference in the pH Activity Pattern of Phosphatase}

Twenty-five strains of 11 different species were subjected to quantitative determinations of their phosphatase activities at a wide $\mathrm{pH}$ range from 3.2 to 10.2. Marked differences were noted from one strain to another in both the $\mathrm{pH}$ activity pattern and the reaction intensity. An example is shown in Fig. 1, in which the pH activity curve is compared among three species, $P$. pseudomallei, P. cepacia, and $P$. aeruginosa. The activity of $P$. pseudomallei was particularly high showing a pattern of acid phosphatase with a pH optimum of 5 to 6 . The activity of $P$. cepacia was lower, though the $\mathrm{pH}$ activity pattern was rather similar to that of $P$. pseudomallei. In contrast, $P$. aeruginosa showed a pattern of alkaline phosphatase as observed in $E$. coli (6). The level of reaction, however, was much lower than those of the above two species.

Such observations were repeated and extended to the other species and strains. The results are summarized in Fig. 2, in which the level of comparative activity and the $\mathrm{pH}$ range for that are shown in combination. Generally speaking, each species has its characteristic phosphatase activity without much strain deviation. P. putida, P. picketti and P. alcaligenes showed typical $\mathrm{pH}$ ranges of alkaline phosphatase similar to that of $P$. aeruginosa, though the latter two species showed very low activities in the reaction. The activities shown by $P$. stutzeri and $P$. pseudoalcaligenes are of acid phosphatase, but the reactions were of negligible levels. $P$. fluorescens and $P$. mendocina exhibited definite acid phosphatase activities with rather narrow $\mathrm{pH}$ ranges. $P$. diminuta was unique in having a 
Table II. Biochemical and biological characters of pseudomonads employed in this study

\begin{tabular}{|c|c|c|c|c|c|c|c|c|c|c|c|}
\hline & 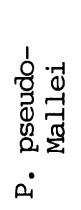 & 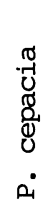 & 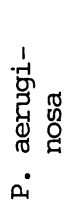 & 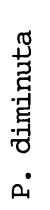 & 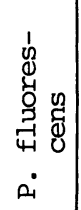 & 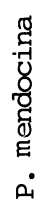 & 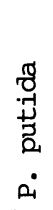 & 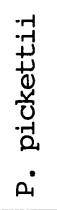 & 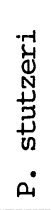 & 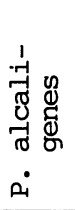 & 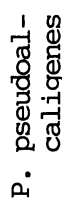 \\
\hline $\begin{array}{l}\text { Acid, (OFBM) } \\
\text { Glucose }\end{array}$ & + & + & + & - & + & + & + & + & + & - & $\mathrm{v}$ \\
\hline Fructose & + & + & $\mathrm{v}$ & - & + & + & + & + & + & - & + \\
\hline Galactose & + & + & $\mathrm{v}$ & - & + & + & + & + & + & - & - \\
\hline Mannose & + & + & $\mathrm{v}$ & - & + & + & + & + & $\mathrm{v}$ & - & - \\
\hline Rhamnose & $\mathrm{v}$ & - & $\mathrm{v}$ & - & $\mathrm{v}$ & - & $\mathrm{v}$ & - & $\mathrm{v}$ & - & - \\
\hline Xylose & $\mathrm{v}$ & + & $\mathrm{v}$ & - & + & + & + & + & + & - & $\mathrm{v}$ \\
\hline Lactose & + & + & - & - & $\mathrm{v}$ & - & $\mathrm{v}$ & $\mathrm{v}$ & - & - & - \\
\hline Sucrose & $\mathrm{v}$ & $\mathrm{v}$ & - & - & $\mathrm{v}$ & - & - & - & - & - & - \\
\hline Maltose & + & + & $\mathrm{v}$ & - & $\mathrm{v}$ & - & $\mathrm{v}$ & $\mathrm{v}$ & + & - & $\mathrm{v}$ \\
\hline Mannitol & + & + & $\mathrm{v}$ & - & + & - & $\mathrm{v}$ & $\mathrm{v}$ & $\mathrm{v}$ & - & - \\
\hline Pyocyanin & - & - & + & - & - & - & - & - & - & - & - \\
\hline Nitrate reduction & $\mathrm{v}$ & $\mathrm{v}$ & $\mathrm{v}$ & - & $\mathrm{v}$ & + & - & + & + & $\mathrm{v}$ & + \\
\hline Gas from nitrate & + & - & $\mathrm{v}$ & - & - & + & - & + & + & $\mathrm{v}$ & - \\
\hline \begin{tabular}{|l|l} 
Oxidase \\
\end{tabular} & + & + & + & + & + & + & + & + & + & + & + \\
\hline $\begin{array}{l}\text { Arginine dihydro- } \\
\text { lase }\end{array}$ & + & - & + & - & + & + & + & - & - & $\mathrm{v}$ & $\mathrm{v}$ \\
\hline $\begin{array}{l}\text { Lysine decarboxy- } \\
\text { lase }\end{array}$ & - & + & - & - & - & - & - & - & - & - & - \\
\hline $\begin{array}{l}\text { Ornithine decar- } \\
\text { boxylase }\end{array}$ & - & $\mathrm{v}$ & - & - & - & - & - & - & - & - & - \\
\hline $\begin{array}{l}\text { Hydrolysis : } \\
\text { Urea }\end{array}$ & $\mathrm{v}$ & $\mathrm{v}$ & $\mathrm{v}$ & - & $\mathrm{v}$ & $\mathrm{v}$ & $\mathrm{v}$ & + & $\mathrm{v}$ & $\mathrm{v}$ & - \\
\hline Esculin & $\mathrm{v}$ & $\mathrm{v}$ & - & - & - & - & - & - & - & - & - \\
\hline DNA & - & - & $\mathrm{v}$ & $\mathrm{v}$ & - & - & - & - & - & - & - \\
\hline Lecithin & $\mathrm{v}$ & $\mathrm{v}$ & - & - & + & - & - & - & - & - & - \\
\hline Gelatin & + & $\mathrm{v}$ & $\mathrm{v}$ & $\mathrm{v}$ & + & - & - & $\mathrm{v}$ & - & - & - \\
\hline Acetamide & - & $\mathrm{v}$ & $\mathrm{v}$ & - & - & - & - & - & - & - & - \\
\hline Growth on : ss & - & - & $\mathrm{v}$ & - & + & $\mathrm{v}$ & + & - & $\mathrm{v}$ & $\mathrm{v}$ & $\mathrm{v}$ \\
\hline Mac Conkey & + & + & + & + & + & + & + & + & + & + & + \\
\hline Cetrimide & - & $\mathrm{v}$ & + & - & + & + & + & - & - & - & $\mathrm{v}$ \\
\hline Acetate & + & + & + & - & + & + & + & + & + & + & + \\
\hline Growth at $42^{\circ} \mathrm{C}$ & + & $\mathrm{v}$ & + & $\mathrm{v}$ & - & + & - & $\mathrm{v}$ & $\mathrm{v}$ & $\mathrm{v}$ & $\mathrm{v}$ \\
\hline Motile & + & + & + & + & + & + & + & + & + & + & + \\
\hline Polartrichous & $>1$ & $>1$ & 1 & 1 & $>1$ & 1 & $>1$ & 1 & 1 & 1 & 1 \\
\hline
\end{tabular}

Sign : $+=908$ or more positive after $24-48 \mathrm{hr}$. of incubation at $30^{\circ} \mathrm{C}$

- $=90 \%$ or more negative after $24-48 \mathrm{hr}$. of incubation at $30^{\circ} \mathrm{C}$

$\mathrm{v}=$ more than 108 and less than $90 \%$ positive 


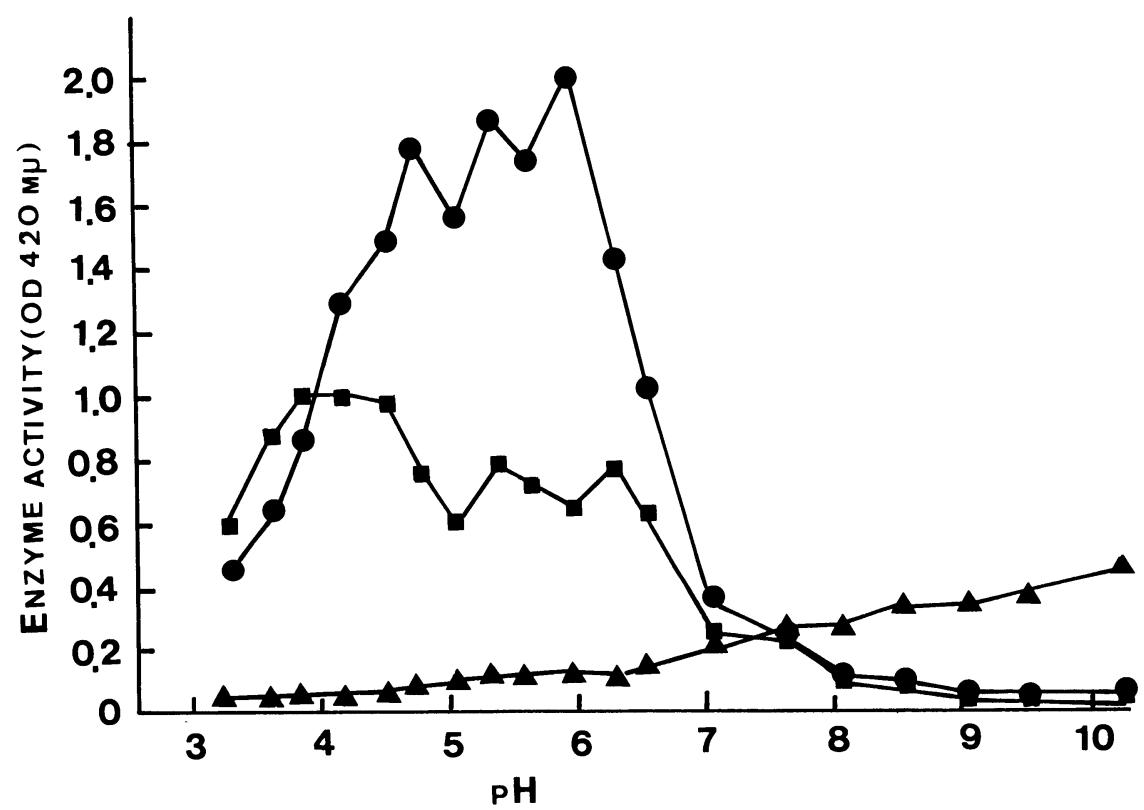

Fig. 1. $\mathrm{pH}$ activity patterns of phosphatase of $P$. pseudomallei, $P$. cepacia, and $P$. aeruginosa.

-—: P. pseudomallei (472/30), - - - P. cepacia (JCM 5510), -A-: P. aeruginosa (JCM 5516)

fairly high level of activity with a wide $\mathrm{pH}$ range from the acid side to the alkaline side, being comparable to $P$. cepacia.

\section{Growth of Pseudomonads in Different $p H$ Environments}

With the above observations in mind, an attempt was made to compare the growths of $P$. pseudomallei, $P$. cepacia, and $P$. aeruginosa in brain heart infusion broth whose $\mathrm{pH}$ was adjusted to 4.0, 4.5, 5.0, 7.0 and 9.0. Broth with each $\mathrm{pH}$ value was dispensed into test tubes in an amount of $3 \mathrm{ml}$, to which $0.1 \mathrm{ml}$ of exponential growth culture of each species was inoculated. Thereafter, the growth was followed with time intervals by measuring the turbidity at $600 \mathrm{~nm}$.

As shown in Fig. 3, $P$. pseudomallei and $P$. cepacia did grow even in the medium of $\mathrm{pH} 4.5$, but $P$. aeruginosa did not. On the other hand, $P$. aeruginosa grew in the environment of $\mathrm{pH} 9.5$, but the growths of the other two species were negligible. In the $\mathrm{pH} 5.0$ and 7.0 environments, the three strains exhibited good adaptability. 


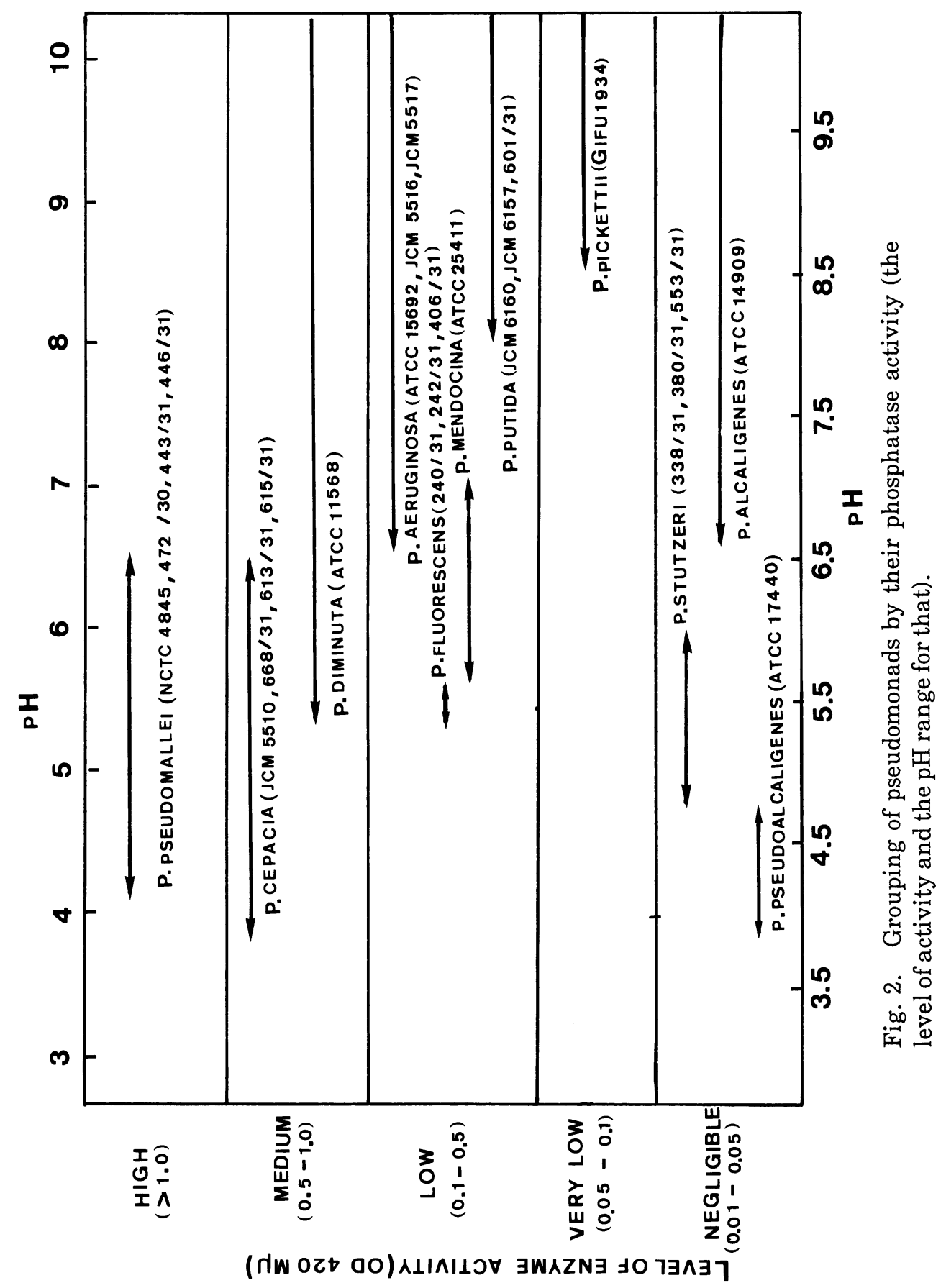




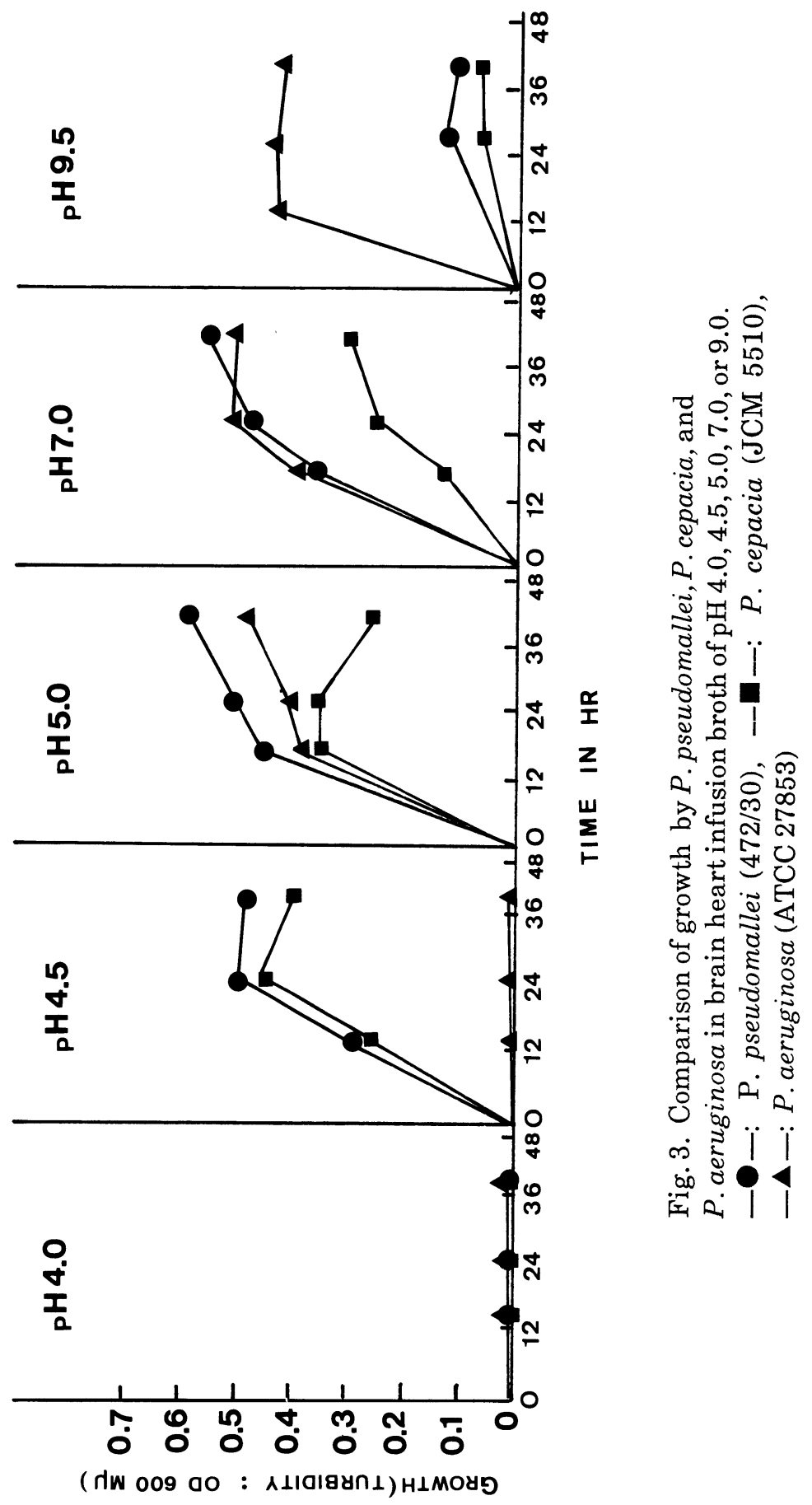




\section{DISCUSSION}

In this study, we evaluated phosphatase activities of members of pseudomonads. Unlike conventional routine methods used in bacterial taxonomy $(7,8)$, evaluation was made quantitatively with a standardized amount of dispersed suspensions. Besides, the enzymatic reaction was determined in a wide range of $\mathrm{pH}$ and read in a relatively short period $(30 \mathrm{~min})$ of incubation so that speciesspecific characters may be emphasized. In this test system, it was revealed that each pseudomonas species has its own $\mathrm{pH}$-activity curve of phosphatase. This aspect of the enzymatic reaction may serve as an identification character in pseudomonad taxonomy. Meanwhile, we were interested also in the bacterial phosphatase activity in relation to their pathogenesis and virulence.

In the case of mycobacteria, every tested species showed acid phosphatase activity (1), virulent tubercle bacilli including $M$. bovis being highest in the level of activity. Likewise in pseudomonads, $P$. pseudomallei, the most pathogenic species, had the highest acid phosphatase activity.

Microbial acid phosphatase has been reported as an enzyme associated with the surface membrane (1,9). In leishmania species (e.g., L. donovani), the acid phosphatase is also a surface membrane enzyme (10) and reported to be 2.4-fold higher in virulent organisms than in avirulent organisms (11).

$P$. pseudomallei (12), tubercle bacilli, and $L$. donovani are all intracellular parasites whose residence is the acidic environment of phagolysosomes $(13,14)$. In this context, we are inclined to suspect that strong acid phosphatase might be a favorable attribute of intracellular parasites (2) for their survival, and that the enzymological characteristics of the surface membrane acid phosphatase are apparently adapted to the living environment of the parasite (15).

Yabuuchi et al. (16) have reported that $P$. pseudomallei and $P$. cepacia can grow in brain heart infusion broth of $\mathrm{pH} 4.5$, but $P$. aeruginosa can not. This observation was confirmed by us here together with an additional finding that $P$. aeruginosa can grow vigorously at $\mathrm{pH} 9.5$, but the former two can not. Thomas et al. (17) recommended the use of nutrient agar plates of $\mathrm{pH} 6.0$ for efficient isolation of $P$. pseudomallei organisms from soil samples. All these observations provide evidence showing that $P$. pseudomallei has a good adaptability an acidic environment to survive and multiply.

The physiologic role of microbial acid phosphatase is not clear, and the mechanism for its probable association with pathogenesis is still a matter of discussion. One explanation for the former may be that the enzyme allows the organisms to obtain necessary orthophosphate from organic phosphate compounds 
for their nutritional demands. For the latter, a hypothetical explanation is that the microbial phosphatase acting on NADPH oxidase of host phagocytic cells interfers with the produciton of toxic oxidative radicals, thereby enhancing the survival of the parasite (2). One of the approaches to this problem is to expand the range of test microbial species to see whether or not acid phosphatase is a universal property specific to intracellular parasites. At the same time, explanation must be obtained also about the biological significance of alkaline phosphatase in $P$. aeruginosa. Is it related with the alkaline environment on the mucous membrane or other places?

Evaluation of phosphatase activity for differentiation of pathogenic strains from nonpathogenic strains of the same or similar species has been reported as a rapid method in mycobacteria $(18,19)$, candida $(20,21)$, and staphylococci $(22,23)$. It is interesting that all these microoganisms have a strong interaction with phagocytes and tend to become intracellular parasites. These studies will be worthy of reexamination from a new angle as stated in this paper.

As for the relation between pseudomonas phosphatase and virulence, Liu (24) reported the heat stability of alkaline phosphatase in such pathogenic species as $P$. aeruginosa and $P$. pseudomallei. Our own experiences on this aspect will be reported elsewhere.

Lastly, we must add that such a gene was recently demonstrated in Salmonella typhimurium, an intracellular pathogen, that is required as a regulatory element for expression of the virulence function in conjunction with nonspecific acid phosphatase (25).

\section{ACKNOWLEDGEMEN'TS}

We are grateful to Dr. R. Murata, Chairman of the Advisory Committee for the Research Promotion Project of National Institute of Health, Thailand, and Dr. Eiko Yabuuchi, Professor of Microbiology, Gifu University School of Medicine, Japan, for their interest and encouragement for our study on P. pseudomallei.

We thank Mrs. Suwanna Tungjitpattanakul for her expert secretarial assistance and Japan Internationl Cooperation Agency (JICA) for financial support to our research project. 


\section{REFERENCES}

1. Kanai, K. (1964): Kekkaku (Tuberculosis), 39, 149-154 (text in Japanese).

2. Glew, R. H., Saha, A., Das, S. and Remaley, A. T. (1988): Microbiol. Rev., 52, 412-432.

3. Chiewsilp, D., Dejsirilert, S., Pornruangvong, S., Kosalanant, V., Ramsiri, and Kobhirunkul, B. (1989): Program \& Abstracts, 1st Natl. Congress Pathol., Faculty of Medicine, Chiang Mai Univ., p. 146.

4. Gilardi, G. L. (1985): In [eds.] E. H. Lennett, S. A. Balow, W. J. Hausler and H. J. Shadomy. Manual of Clin. Microbiol, p.350-371. Amer. Soc. Microbiol., Washington, D. C. 20006.

5. Rrubin, S. J., Granato, P. A. and Wasilauskas, B. L. (1985): In [eds.] E. H. Lennett, S. A. Balow, W. J. Hausler and H. J. Shadomy. Manual of Clinical Microbiology, p.330-349. Amer. Soc. Microbiol., Washington, D. C. 20006.

6. Torriami, A. (1960): Biochim. Biophys. Acta, 38, 460-479.

7. Killian, M. (1976): J. Gen. Microbiol., 93, 9-62.

8. Satta, G., Pompei, R., Grazi, G. and Cornaglia, G. (1988): J. Clin. Microbiol., 26, 2639-2641.

9. Walther, P., Muller, M. and Schweingruber, M. E. (1984): Arch. Microbiol., 137, 128-134.

10. Dwyer, D. M. (1981): Science, 212, 939-941.

11. Katakura, K. and Kobayashi, A. (1988): Infect. Immun., 56, 2856-2860.

12. Figgott, M. J. A. and Hochholzer, L. (1970): Arch. Pathol., 90, 101-111.

13. Sprick, M. G. (1956): Amer. Rev. Tuberc., 74, 552-565.

14. Ohkuma, S. and Poole, B. (1978): Proc. Natl. Acad. Sci., U.S.A., 75, 33273331 .

15. Gottlieb, M. and Dwyer, D. M. (1981): Exptl. Parasitol., 52, 117-128.

16. Yabuuchi, E., Miyajima, N., Hotta, H., Ohyama, A. and Tanaka, N. (1970): Med. J. Osaka Univ., 21, 1-6.

17. Thomas, A. D., Forbes-Faulkner, J. and Parker, M. (1979): Amer. J. Epidemiol., 110, 515-521.

18. Kappler, W. (1965): Beitr. Klin. Erforsch. Tuberk. Lungkr., 130, 225-226.

19. Andrejew, A. (1968): Ann. Inst. Pasteur (Paris), 115, 11-22.

20. Amith, R. F., Blasi, D. and Dayton, S. L. (1973): Appl. Microbiol., 26, 364367.

21. Farid, A., Atia, M. and Hassouna, M. (1980): Mykosen, 23, 640-643.

22. Barber, M. and Kuper, S. W. A. (1951): J. Pathol. Bacteriol., 63, 65-68.

23. White, M. L. and Pickett, M. J. (1953): Amer. J. Clin. Pathol., 23, 1181-1183.

24. Liu, P. V. (1966): Amer. J. Clin. Pathol., 45, 639-642.

25. Fields, P. I., Groisman, E. A. and Heffron, F. (1989): Science, 243, 1059-1062. 